University of Nebraska - Lincoln

DigitalCommons@University of Nebraska - Lincoln

Robert Katz Publications

Research Papers in Physics and Astronomy

January 1965

Physics-Mathematics Building at Kansas State University

Robert Katz

University of Nebraska-Lincoln, rkatz2@unl.edu

Follow this and additional works at: https://digitalcommons.unl.edu/physicskatz

Part of the Physics Commons

Katz, Robert, "Physics-Mathematics Building at Kansas State University" (1965). Robert Katz Publications. 12.

https://digitalcommons.unl.edu/physicskatz/12

This Article is brought to you for free and open access by the Research Papers in Physics and Astronomy at DigitalCommons@University of Nebraska - Lincoln. It has been accepted for inclusion in Robert Katz Publications by an authorized administrator of DigitalCommons@University of Nebraska - Lincoln. 
American Journal of Physics (January 1965) Volume 33, Issue 1, pp. 45-50

\title{
Physics-Mathematics Building at Kansas State University
}

\author{
Robert Katz \\ Kansas State University, Manhattan, Kansas
}

(Submitted March 16, 1964)

\begin{abstract}
A building of about 134000 -sq ft area, containing research rooms, shops, store rooms, three lecture halls, classroom, and offices, for the Departments of Physics and of Mathematics has been completed at Kansas State University. Details concerning the construction, the provision of laboratory facilities, and special features of the building are given, as are floor plans and statements of costs involved.
\end{abstract}

C1965 American Association of Physics Teachers. Used by permission.

Online at $\underline{\mathrm{http}} / / / \mathrm{scitation}$.aip.org/dbt/dbt.jsp?KEY=AJPIAS\&Volume $=33 \& I s s u e=1$

doi:10.1119/1.1971229 


\title{
Physics-Mathematics Building at Kansas State University
}

\author{
ROBERT KATZ \\ Kansas State University, Manhattan, Kansas
}

(Received 16 March 1964)

\begin{abstract}
A building of about 134000 -sq ft area, containing research rooms, shops, store rooms, three lecture halls, classroom, and offices, for the Departments of Physics and of Mathematics has been completed at Kansas State University. Details concerning the construction, the provision of laboratory facilities, and special features of the building are given, as are floor plans and statements of costs involved.
\end{abstract}

$T$ HE physics-mathematics building at Kansas State University is a contemporary reinforced concrete structure faced with native limestone, so as to be compatible with other campus buildings. The building serves the needs of the departments of physics and mathematics for laboratory, classroom, and office space, and provides large lecture halls for introductory courses, especially in physics and physical science. An observatory, a planetarium, a computer center, an accelerator laboratory, and a meteorological station are also contained within the structure.

The building is an assembly of five structurally independent units. All elements of the building except for the roofs over the large lecture halls, are framed in reinforced concrete. All units are built on undisturbed soil with a foundation of spread footings at a maximum soil pressure of
$4000 \mathrm{lbs}$ per sq ft, protected by a 6-in.-diam corrugated metal pipe perimeter underdrain, with graded aggregate backfill.

An architect's rendering of the building is shown in Fig. 1, and a floor plan is shown in Fig. 2. The largest of the five units, area A, consisting of research rooms, classrooms, and teaching laboratories, is framed using two-way flat slab with drop panels, and without column caps. Three framed floors and roof with regular bays of $22 \times 24 \mathrm{ft}$ make this an economical structural frame, mainly because of simplicity and reuse of forms. The flat slab reduces story heights and allows greater freedom for mechanical installations. The roof of area A is readily accessible for experimental purposes. The basement of this unit contains research laboratories and a computing center which presently houses an IBM 1401-1410 digital computer. Its main floor contains offices

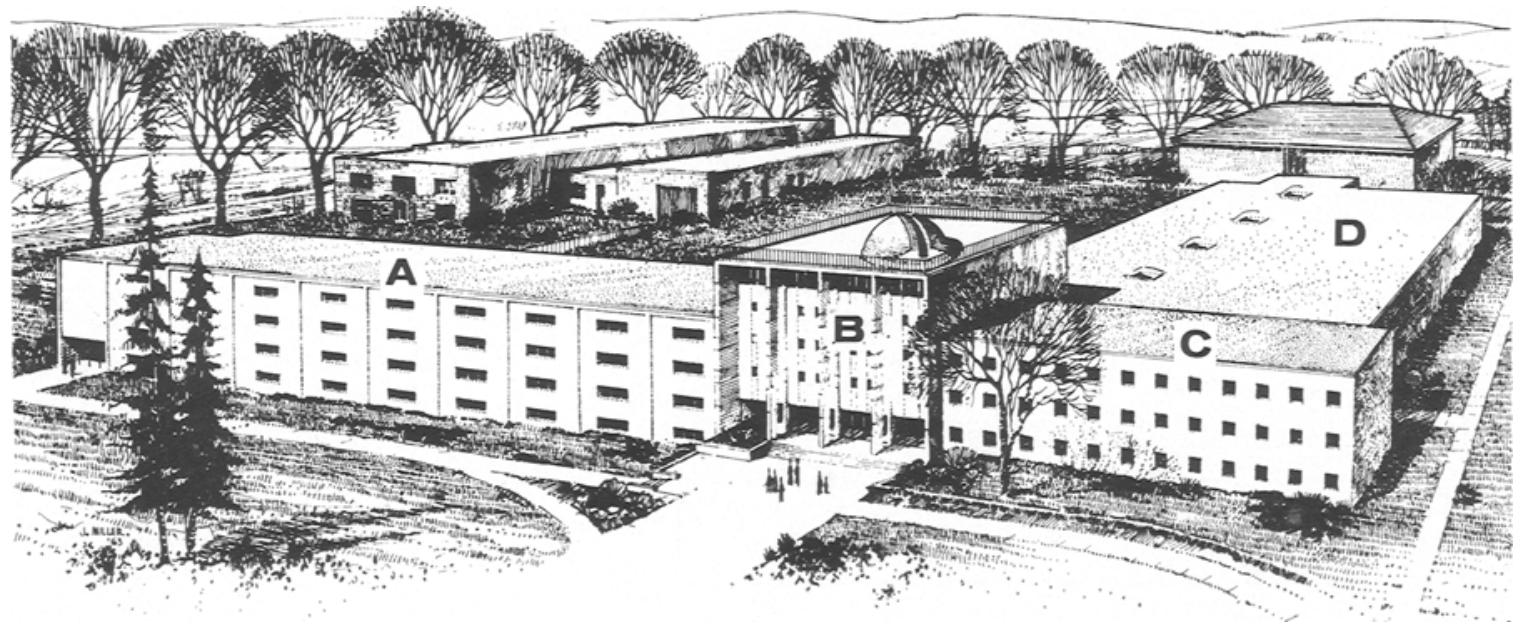

Frg. 1. Physics-Mathematics building at Kansas State University. Area A consists of offices and teaching laboratories, area $B$ is the utility core with planetarium and observatory on the upper two stories, area $C$ consists of offices and research laboratories, and area D consists of lecture halls, classrooms, shops, storage, and research laboratories. 


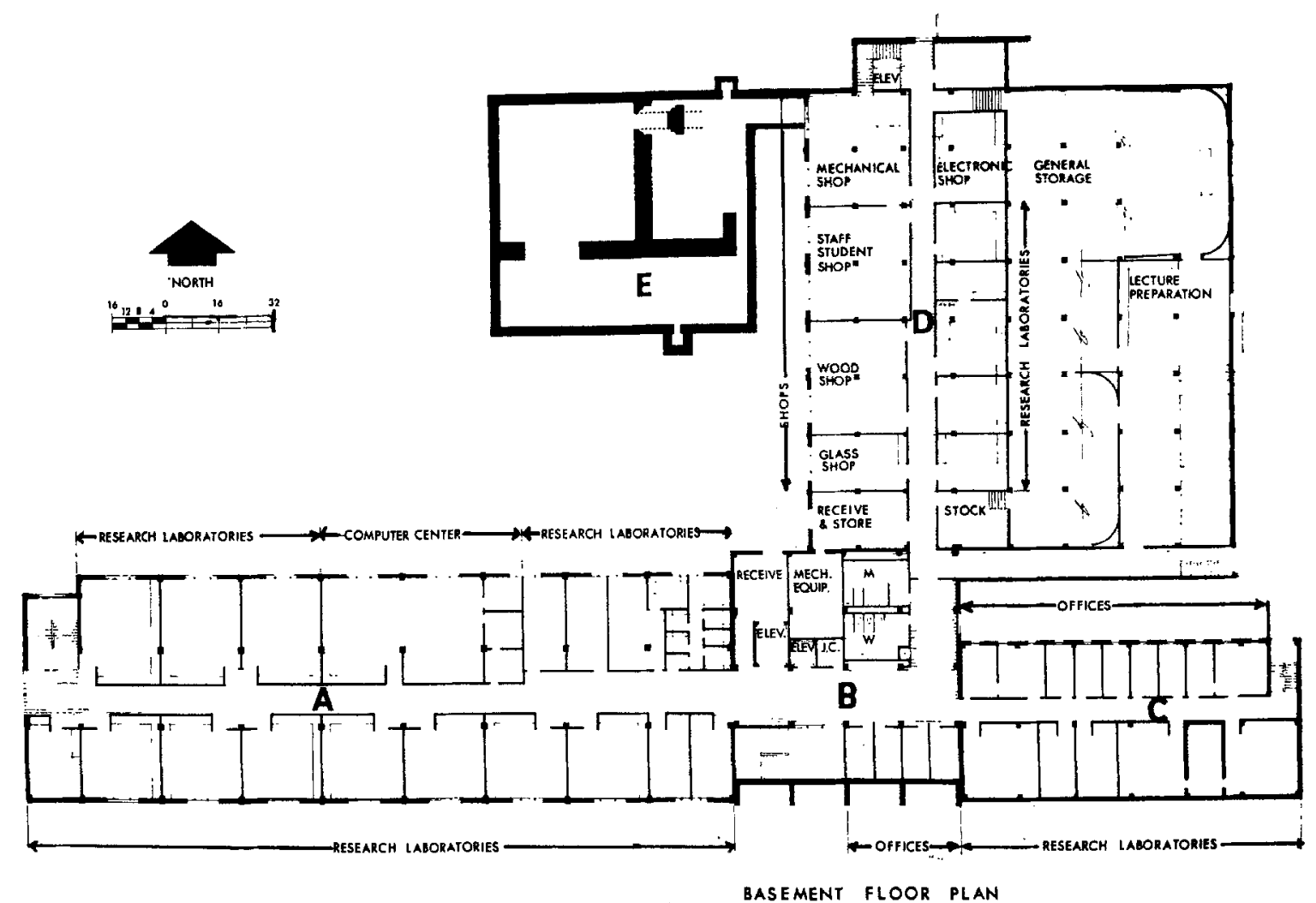

(a)
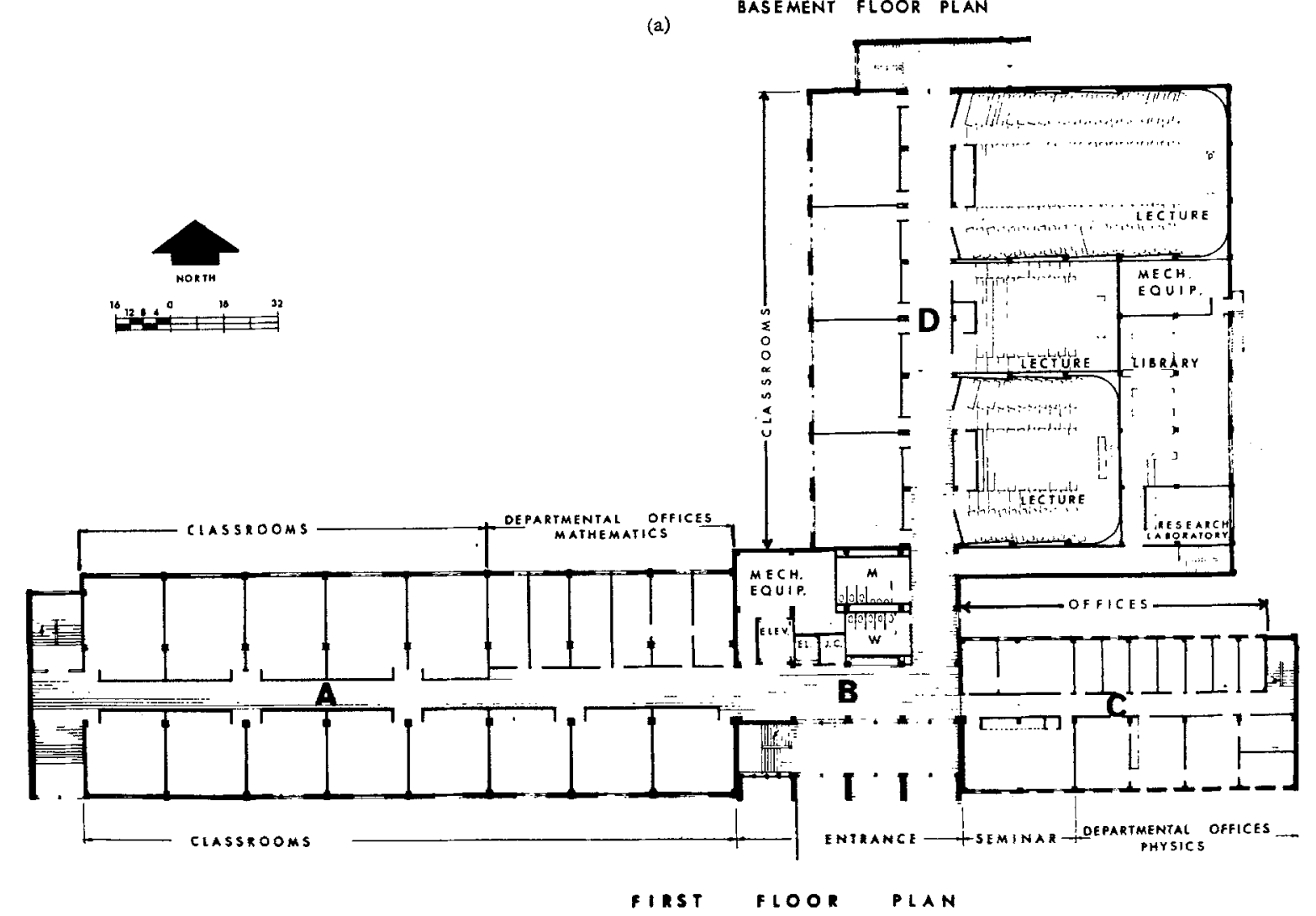

(b) 


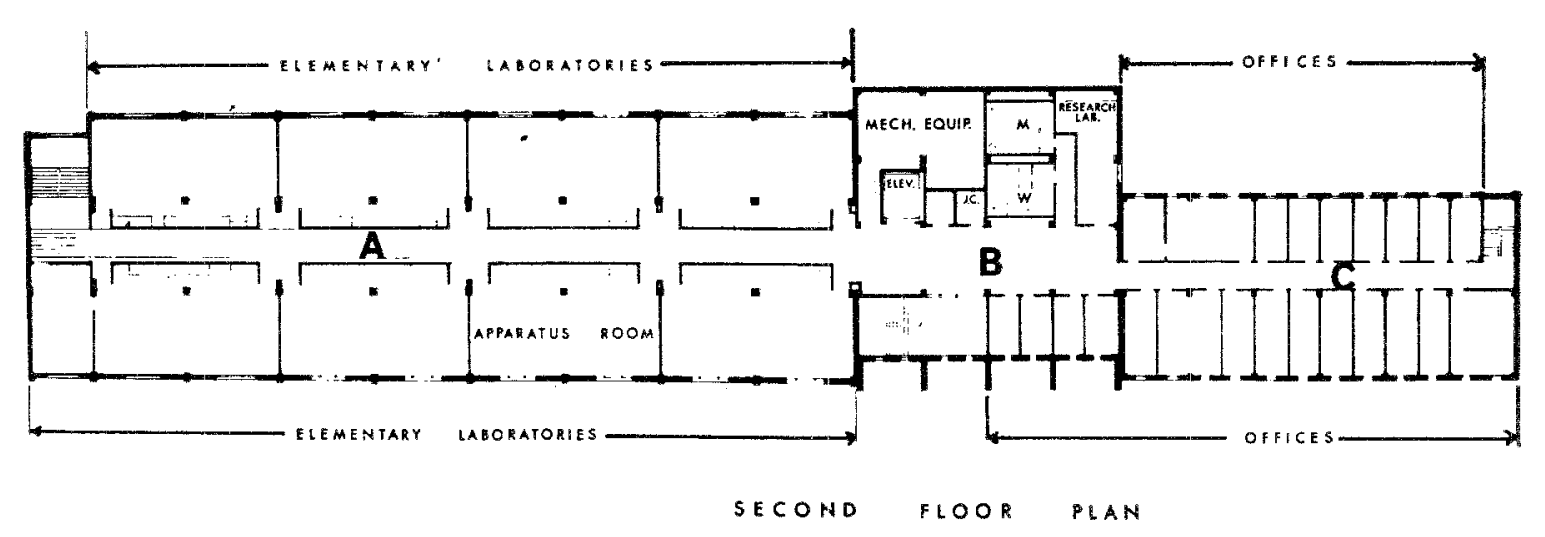

(c)
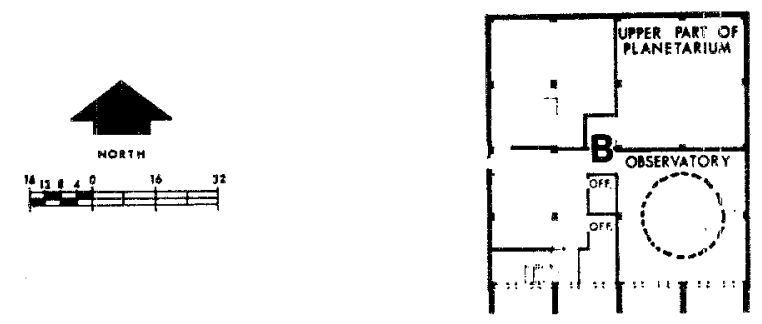

FIFTH FLOOR PLAN
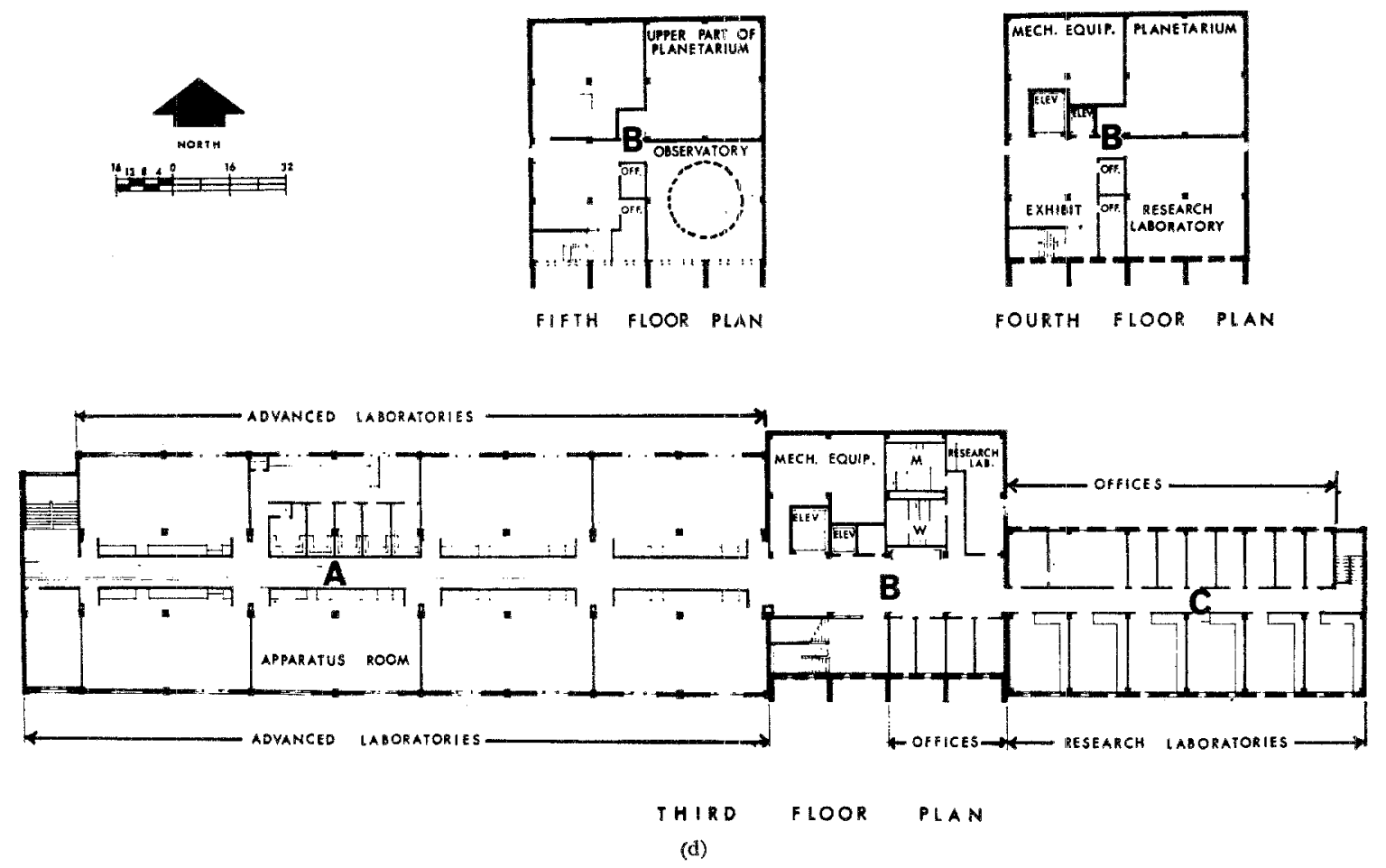

Frg. 2. Floor plans.

of the department of mathematics, eight classrooms having seating space for 30 students each, and five classrooms having seating space for 40 students each. On the second floor there is a teaching laboratory suite for introductory courses in physics which can accommodate a total of 150 students at one time, while the third floor contains a similar laboratory suite for advanced laboratories which can accommodate a total of 100 students at one time. Each laboratory suite has a storage room containing a panel for the distribution of electrical services to its suite, the services being routed from a distribution panel connected to the ac building supply. Battery and generator carts may be connected to the distribution panel by patch cords. Carts and panels were manufactured by the Hampden Engineering Corporation, East Longmeadow, Massachusetts. The laboratories contain movable tables and are served with electricity from drop cords, one of which is permanently connected to the ac supply, and the other to the laboratory panel board. Each laboratory is provided with a double sink, workbench, and storage cabinet, and is sup- 
plied with hot and cold water and gas. Unistrut channels are built into the laboratory walls. Two suites of darkrooms are provided, one in the basement and the other on the third floor as part of the advanced laboratory. Two chemistry rooms are contained in this area, one in the basement and the other on the third floor, and are provided with fume hoods and the customary facilities. Chemistry laboratories, selected research rooms, and darkrooms are piped for distilled water distributed from a steam operated still. Fume hoods have been placed in other selected laboratories, according to need.

The main entrance, offices, the utility core, the planetarium (Spitz A-3-P) and the observatory (containing an 18-in. Cassegrainian reflecting telescope built by the Cave Optical Company, Los Angeles, under a 22-ft-diam dome) constitute area $B$, which has five levels above a basement. Hydraulic elevators provide passenger and freight service to the fourth floor, making it possible to service the roof of area A. Interior stairs give access to the observatory on the fifth floor, and exterior stairs give access to the roof of area $\mathrm{B}$, where meteorological observing equipment is mounted. A shaft for a celostat is also provided here.

The offices of the department of physics and an adjoining seminar room are on the main floor of area C. Faculty and student offices and research rooms are distributed throughout the unit. Individual faculty offices are $7 \frac{1}{2} \times 15 \mathrm{ft}$. Typical research rooms are $15 \times 20 \mathrm{ft}$ and are provided with gas, sink, and storage cabinets on one wall, and a Unistrut channel on the other. Laboratories are supplied with electricity by a $208 / 120 \mathrm{~V}, 4$ wire bus duct. Other electrical supplies are available through battery and generator carts, as in the teaching laboratories. Each floor contains a graduate student office of $15 \times 25 \mathrm{ft}$ which is provided with cubicles and an adjoining conference room.

Lecture halls, lecture preparation rooms, research rooms, classrooms, a research library, shops, and storage are provided in area $\mathrm{D}$. The unit is framed using one-way slabs and beams, except for the roofs over the lecture halls where long span steel beams are utilized. The roof over these joists is of lightweight insulating concrete on galvanized high-strength corrugated steel deck. Four large classrooms, each seating 50 students, and three rectangular lecture halls seating 340,178 , and 110 students are provided, all having access from the main floor at the rear of the lecture hall. Coat racks are installed in the hallway outside the lecture halls. Fixed pedestal seats with fixed right-hand writing arms and underseat book storage are spaced two feet apart in rows three feet apart. The small lecture halls slope down to the lecture desk at an angle of $20^{\circ}$ while the slope angle is $10^{\circ}$ in the large hall. White surfaced lecture desks are at the level of the basement floor, where the preparation room is located. All lecture halls are served by a large preparation room $30 \times 80 \mathrm{ft}$ which contains lecture apparatus and an electrical panel board. Lecture tables are provided with electricity, gas, vacuum, and compressed air. Each hall has two Unistrut channels in the ceiling directly forward of the lecture table, a projection booth at the rear, an integral sound system with controls at the lecture table, ceiling mounted speakers, both wired and wireless microphones, fixed slate chalkboards, and an electric-powered roll-mounted projection screen of adequate size. Each hall is illuminated with fluorescent lamps to about 30 $\mathrm{ft}-\mathrm{C}$; this may be supplemented or replaced by dimmer controlled incandescent lighting which provides another $30 \mathrm{ft}-\mathrm{C}$. Chalkboards have supplementary fluorescent lamps in reflector housings directly above them. Additional ceiling spotlights are provided for the lecture table. Lecture halls have minimal acoustic treatment. Controls are provided at the lecture table so that a motion picture projector may be started from the lecture table, and so that $2-\times 2$-in. slides may be changed without requiring an operator to be present during the lecture. A tape recorder can be incorporated in to the sound system. No provision has been made for television or for elaborate staging. Space has been provided around the lecture tables for wheeled extensions. The research library $(30 \times 80 \mathrm{ft})$ is on the main floor behind the lecture halls and above the lecture preparation room, where it is isolated from noise and from the main stream of traffic. Shops are in the basement of this area. A mechanicians shop of $1100 \mathrm{sq} \mathrm{ft}$, a staff-student shop of $1250 \mathrm{sq} \mathrm{ft}$, a wood shop of $1000 \mathrm{sq} \mathrm{ft}$, a glass shop of $750 \mathrm{sq} \mathrm{ft}$, and an electronics shop of $500 \mathrm{sq} \mathrm{ft}$, are provided. 
A storeroom is in the same section across the hall from the shops and there is a large subbasement storage area beneath the sloping floor of the lecture halls.

Area $\mathrm{E}$ is designated to receive a low energy accelerator, and is in a subbasement adjoining area $D$, with access through a stairwell and a hydraulic lift. The area is framed with thick reinforced concrete members. Wall thicknesses are up to $4 \mathrm{ft}$, as required by the function of the area.

In the design of the structure emphasis has been placed upon function. The main portion of the building (areas $A, B$, and $C$ ) is in the form of a narrow rectangle, aligned east-west, so that windows face north or south to minimize insolation. There are no glass walls or window walls, to diminish the air conditioning burden. Lecture halls are windowless. All offices and classrooms are provided with small windows, used in combination with small sections of fixed glazing in classrooms and laboratories. Venetian blinds capable of darkening rooms to a level suitable for showing slides or performing many optical experiments are mounted on all windows. All interior walls are of painted haydite block, with double walls between adjoining lecture halls. While generally adequate, this material transmits sound a little too freely for comfort in adjoining offices. Care must be taken in mounting chalkboard so that writing noises are not transmitted through the wall to adjoining classrooms. Hallways have been provided with a $5-\mathrm{ft}$ 3 -in. wainscote of glazed tile. Stairs and entrance corridors are floored with ceramic tile. All toilets are fully ceramic tiled. All other floors are of vinyl asbestos tile. Plumbing and ductwork are exposed, except for dropped ceilings in halls, offices, and lecture halls. Compressed air is supplied as needed by small units strategically placed throughout the building. Ceilings in classrooms and laboratories are spray coated with acoustic plaster. Floor drains were specified for all laboratories. All classrooms are provided with fixed slate chalkboards covering three interior walls. Four foot doors have been used in all classrooms and laboratories, and additional passthrough units have been mounted in the wall next to the door in research laboratories to pass electrical cable or hose from pumps or gener- ators in the halls, as needed. In adjacent laboratories plumbing has been mounted on a similar wall (rather than on opposite sides of the same wall). In this way water, gas, and a drain are readily accessible to equipment stationed at the blank wall of one laboratory, from its neighboring laboratory room. Power distribution throughout the building is by a $208 / 120 \mathrm{~V}, 4$ wire secondary from a centrally located transformer of 750-kVA capacity. Electrical distribution to research laboratories is through plug in power bus duct. As previously indicated distribution panels are provided for each of the two teaching laboratory suites from its own storeroom, and for the lecture halls from the lecture preparation room. All other electrical service is through rectifier carts or battery carts, as previously described. There is no central switchboard, no battery room or generator room.

The building is heated in cold weather by an automatically controlled hot water heating system in which water from centrally located heating and pumping equipment is circulated in a piping system throughout the building to convector-type heating units in the rooms. The central heating equipment is supplied with steam piped from the university power plant. The building is cooled and ventilated by centrally located equipment that supplies air through duct systems to all rooms and that is automatically controlled to supply the quantity and condition of air required for ventilation, comfort, and make-up of exhaust air. One large general system whose capacity is $96000 \mathrm{ft}^{3} / \mathrm{min}$ supplies the academic areas, and smaller systems whosecapacities total $24000 \mathrm{ft}^{3} / \mathrm{min}$ supply each of the three lecture halls, the planetarium, the computing center, and the accelerator room. Chilled. water from the university power plant is piped to coils in the air systems for cooling the air supplied to the building. In general, cold air at $60^{\circ} \mathrm{F}$ is supplied to air ducts at each room all the year long. In summer, this air is cooled by air conditioning units. In winter, outside air is heated to this temperature by coils supplied with steam from the university power plant. Individual thermostats in each room control the flow of cold air to the room, and in winter, the flow of hot water to the convector heating units. Under max- 
imum conditions 400 tons of refrigeration are needed to cool the building.

The initial building program was prepared by the faculty of the physics and mathematics departments in September 1958, after two years of exploratory discussions, and the building was occupied in September 1963, five years later. The total cost of the building (including all furniture, built-in cabinet work, utility connections, air conditioning, walks, roadways, and landscaping) was $\$ 2236000$. With the exception of $\$ 200000$ contributed by the National Science Foundation, this amount was supplied by the State of Kansas. The floor area of the building is $133800 \mathrm{sq} \mathrm{ft}$, so that the cost of the building was $\$ 16.70$ per sq ft. An additional $\$ 689000$ was expended for physics research and teaching equipment, and for the expense of moving from previously occupied quarters (approximately $\$ 32000$ ). Additional equipment has been and is being added by grants from industry and foundations.

The building was designed by F. O. Wolfenbarger and Associates, Manhattan, Kansas, and the consulting engineering firms of Scott and Kinney, Kansas City, Missouri, and Finney and Turnipseed, Topeka, Kansas, all working under the supervision of the State Architect's Office. The building was constructed by Hunter and Lundberg, Manhattan, Kansas, general contractors, Evans Electrical Construction Company, Kansas City, Missouri, electrical contractors, and Kendall Plumbing Inc., Wichita, Kansas, mechanical contractors. 